\title{
Cystic fibrosis, atopy, and airways lability
}

\author{
M. SILVERMAN, F. D. R. HOBBS, I. R. S. GORDON, AND F. CARSWELL \\ From the Departments of Child Health and Radiology, Royal Hospital for Sick Children, Bristol
}

SUMmaRY In a survey of cystic fibrosis (CF) in the Avon area, 48 children with CF from 40 families together with 71 of their parents were studied by spirometry, exercise tests, and pinch tests. A control group of 42 young adults was similarly tested; control data for children were taken from previously published work. The prevalence of atopy (any positive prick test) in children with CF was $48 \%$. Sensitivity to grass pollens and house dust mite was no more common in these children $(29 \%)$ than in a normal population (34\%). Hypersensitivity to Aspergillus fumigatus was found in $35 \%$ of children with CF and was associated with severe lung disease. The parents had a normal pattern and prevalence of atopy. Exercise-induced airways obstruction was present in only $22 \%$ of children with CF; its association with severe lung disease rendered interpretation difficult. The parents had a normal response to exercise. Both hypersensitivity to $A$. fumigatus and exerciseinduced airways lability had the features of acquired characteristics. There was nothing in the present study to support the hypothesis that the possession of a CF gene predisposed to atopy.

The prevalence and importance of allergic disease in children with cystic fibrosis (CF) is a topic of dispute. Some studies have shown a high prevalence of allergic (or atopic) respiratory disease (Warren et al., 1975; Warner et al., 1976a), whereas others have failed to show any difference in prevalence between children with CF and normal children (Kulczycki et al., 1961; Rachelefsky et al., 1974). Likewise, it has been suggested by some that atopic hypersensitivity in $\mathrm{CF}$ is associated with severe lung disease (Warner et al., 1976a), and by others, with relatively mild lung disease (Rachelefsky et al., 1974).

Similarly, the prevalence of allergic disease in the parents of children with $\mathrm{CF}$ has varied in different studies. Some workers have found an association between atopy and the CF gene (McFarlane and Allan, 1976; Warner et al., 1976b), while the evidence of others seems to contradict this (Counahan and Mearns, 1975). Many studies have been based on data collected at specialist referral centres, patients attending such centres being highly selected and unrepresentative of the total population of patients with CF.

We studied prospectively, the families of children with CF living within a defined geographical area. As well as measuring lung function and atopic hypersensitivity, we assessed airways lability in the children and their parents.

Received 6 February 1978

\section{Subjects and methods}

Children with CF currently living within the Avon area were traced through their records at the Royal Hospital for Sick Children and Southmead Hospital, Bristol. 40 of 42 families approached (48 children and 71 parents) agreed to take part in the study (Table 1). Six single-parent families and 3 parents who refused to co-operate accounted for the missing parents. $\mathbf{4 2}$ medical students acted as controls. No subject had received any bronchodilator, antihistamine, or antiasthma drug on the test day.

After a history had been recorded for each subject, peak expiratory flow rate (PEFR) was measured using a Wright peak-flow meter, and a forced expiratory spirogram, for calculating forced expiratory volume in one second $\left(F E V_{1}\right)$, maximum midexpiratory flow rate (MMFR), and forced vital capacity (FVC), was recorded using a Vitalograph spirometer. Normal values for lung function for

Table 1 Subjects

\begin{tabular}{llll}
\hline & $\begin{array}{l}\text { CF } \\
\text { children }\end{array}$ & Parents & $\begin{array}{l}\text { Adult } \\
\text { controls }\end{array}$ \\
\hline Total no. (years) & 48 & 71 & 42 \\
Mean age (y. & $7 \cdot 6$ & 36 & 22 \\
Sex (M/F) & $24 / 24$ & $32 / 39$ & $28 / 14$ \\
Tests & & & \\
$\quad$ pulmonary function & 42 & 69 & 42 \\
$\quad$ exercise & 36 & 68 & 42 \\
prick tests & 48 & 71 & 42 \\
\hline
\end{tabular}


children were taken from Godfrey et al. (1970) and Cogswell et al. (1975), and for adults from Cotes (1975). Not all the children were old enough to perform lung function tests, or the exercise tests which followed (Table 1); heart disease and advanced pregnancy were reasons for some of the parents not completing all the investigations.

Exercise testing consisted of continuous running for $6 \mathrm{~min}$ on a treadmill set at a speed and slope calculated to produce a final heart rate of about 170/min (Silverman and Anderson, 1972). PEFR (the best of 3 attempts on each occasion) was recorded before, during, and for $20 \mathrm{~min}$ after exercise. Pulse rate was counted at the end of exercise. Two indices of airways lability were calculated: (1) the rise in PEFR during exercise ( $\%$ of the initial value), and (2) the fall in PEFR after exercise (\% of the initial resting value). The values of these indices in 60 normal children were obtained from Anderson (1972).

Prick (intracutaneous) tests were performed on the forearm, by a standard technique (Pepys, 1975), using the following 10 Bencard extracts of common antigens: Dermatophagoides pteronyssinus, mixed grasses, Cladosporium, Alternaria, Aspergillus fumigatus, Candida species, milk, egg, cat, and dog. A weal of more than $2 \mathrm{~mm}$ at $15 \mathrm{~min}$ was accepted as positive, in the absence of any reaction to the control solution. In the present study atopy is defined as the manifestation of immediate hypersensitivity to at least one of the antigens tested. The prevalence of atopy in normal children was obtained from Godfrey and Griffiths (1976).

For each child with CF, a recent chest $x$-ray was inspected by one of us (I.R.S.G.) without knowledge of any other result, and assessed according to the system of Chrispin and Norman (1974), to give the $x$-ray score. The higher the score, the worse the disease.

Approval for the study was obtained from the Bristol Health District Ethical Committee.

Results were analysed by $\chi^{2}$ tests (including Yates's correction for small numbers) or by $t$ tests for unpaired samples (Swinscow, 1977).

\section{Results}

Atopy. The prevalence of atopy (as defined above) of $48 \%$ (Table 2) was higher in children with $\mathrm{CF}$ than in normal schoolchildren, but the difference was not significant $\left(\chi^{2}=3.49 ; 0.1>P>0.05\right)$. Considering only hypersensitivity to $D$. pteronyssinus and grass pollens, $29 \%$ of CF children were atopic and the distribution of hypersensitivity to these 2 agents was not significantly different from the value of $34 \%$ in normal children (Godfrey and Griffiths,
Table 2 Prevalence of atopy

\begin{tabular}{|c|c|c|c|c|}
\hline & \multicolumn{2}{|c|}{ Children } & \multicolumn{2}{|l|}{ Adults } \\
\hline & $C F$ & Controls* & Parents & Controls \\
\hline No. tested & 48 & 303 & 71 & 42 \\
\hline $\begin{array}{l}\text { Oyerall prevalence } \\
(\%)\end{array}$ & 48 & 34 & 34 & 40 \\
\hline $\begin{array}{l}\text { Sensitive to }(\%) \\
\text { D. pteronyssinus } \\
\text { Mixed grasses } \\
\text { A. fumigatus }\end{array}$ & $\begin{array}{l}13 \\
25 \\
35\end{array}$ & $\begin{array}{r}26 \\
24 \\
-\end{array}$ & $\begin{array}{r}20 \\
18 \\
0\end{array}$ & $\begin{array}{r}26 \\
26 \\
0\end{array}$ \\
\hline
\end{tabular}

*From Godfrey and Griffiths (1976).

1976). Among the parents, neither the overall prevalence of atopy nor the distribution of hypersensitivity was significantly different from that in normal adult controls (Table 2). Nor was there any association between atopy in the children with $\mathrm{CF}$ and in their parents $\left(\chi^{2}=0.38 ; P>0.5\right)$.

However $35 \%$ of $\mathrm{CF}$ children showed immediate hypersensitivity to $A$. fumigatus extract. The prevalence of hypersensitivity to Aspergillus appeared to increase with age up to 12 years, in contrast to the relatively stable prevalence of immediate hypersensitivity to other allergens (Figure). There were too few children in the 13-16 age group to draw any conclusions on the prevalence of Aspergillus sensitivity in the oldest children.

When the total population of children with CF was divided into 3 groups according to atopic status (Table 3), several differences became apparent. The Aspergillus hypersensitive group was significantly older than the others, and respiratory disease, assessed radiologically or by means of lung function tests, was significantly worse in children with

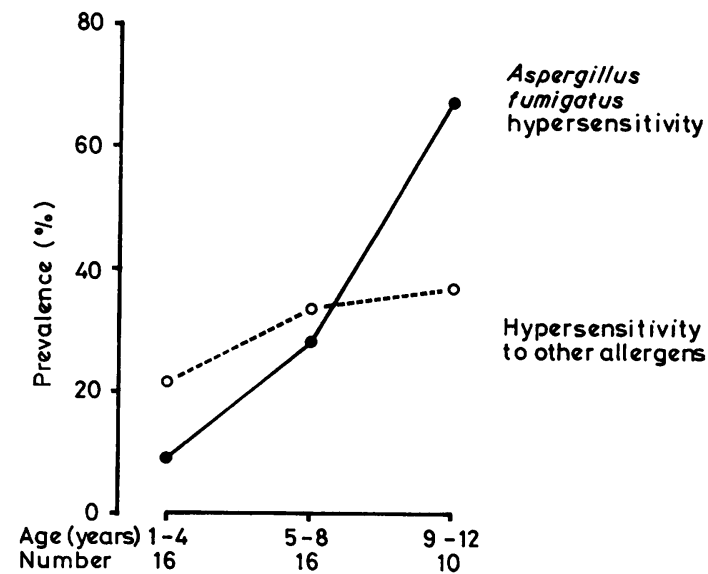

Figure Changing prevalence of hypersensitivity with age in children with cystic fibrosis. 
Aspergillus hypersensitivity than in the other 2 groups. When the age difference between the Aspergillus hypersensitive group and the other 2 groups was eliminated by age-matching, the Aspergillus hypersensitive patients still had significantly higher mean scores in their chest $x$-rays and lower mean PEFR and MMFR. An association was found between hypersensitivity to $A$. fumigatus and hypersensitivity to other allergens $\left(\chi^{2}=4.31 ; P<0.05\right)$, suggesting that hypersensitivity to $A$. fumigatus was more likely to be found in an otherwise atopic patient than in an otherwise nonatopic patient.

The nonatopic CF children and the group sensitive to allergens other than $A$. fumigatus were similar in respect to their mean ages, $x$-ray scores, and PEFRs. However the nonatopic patients had a lower mean MMFR $(t=2.5 ; \mathrm{P}<0.05)$, implying more severe airways obstruction.

Airways ${ }^{\top}$ lability. Exercise-induced airways lability (Table 4) was no more severe in CF children or their parents than in controls and there was no association between airways lability in CF children and their parents $\left(\chi^{2}=0.32 ; P<0.5\right)$.

Although numbers were small, the children with higher airways lability (fall in PEFR after exercise of greater than $10 \%$ ) appeared to have a greater

Table 3 Clinical features in relation to atopy and Aspergillus hypersensitivity in CF children

\begin{tabular}{|c|c|c|c|}
\hline & \multirow[t]{2}{*}{ Nonatopic } & \multicolumn{2}{|l|}{ Atopic } \\
\hline & & $\begin{array}{l}\text { Sensitive to } \\
\text { A. fumigatus } \\
\text { ( } \pm \text { other } \\
\text { allergens) }\end{array}$ & $\begin{array}{l}\text { Sensitive to } \\
\text { other } \\
\text { allergens } \\
\text { only }\end{array}$ \\
\hline No. & 25 & 17 & 6 \\
\hline $\begin{array}{l}\text { Age (years) } \\
\text { Chest } x \text {-ray score } \\
\text { PEFR ( } \% \text { predicted) } \\
\text { MMFR ( } \% \text { predicted) }\end{array}$ & $\begin{array}{c}6 \cdot 5(4 \cdot 3) \\
5 \cdot 9(4 \cdot 2) \\
102(24) \\
56(18)\end{array}$ & $\begin{array}{l}9 \cdot 8(3 \cdot 9) \\
10 \cdot 3(6 \cdot 5) \\
68(21) \\
35(24)\end{array}$ & $\begin{array}{l}6 \cdot 2(3 \cdot 4) \\
5 \cdot 8(3 \cdot 7) \\
105(33) \\
84(29)\end{array}$ \\
\hline
\end{tabular}

Mean values \pm 1 SD.

Table 4 Exercise-induced airways lability

\begin{tabular}{|c|c|c|c|c|}
\hline & \multicolumn{2}{|l|}{ Children } & \multicolumn{2}{|l|}{ Adults } \\
\hline & $C F$ & Controls* & Parents & Controls \\
\hline \multirow{5}{*}{$\begin{array}{l}\text { No. } \\
\text { PEFR before exercise } \\
\text { (\% predicted) } \\
\text { Rise in PEFR during } \\
\text { exercise (\%) } \\
\text { Fall in PEFR after } \\
\text { exercise (\%) } \\
\text { Heart rate at end of } \\
\text { exercise (per min) }\end{array}$} & 36 & 60 & 67 & 42 \\
\hline & $90(25)$ & 97 (14) & $102(15)$ & $96(11)$ \\
\hline & $9 \cdot 0(9 \cdot 3)$ & $8 \cdot 2(5 \cdot 4)$ & $7 \cdot 6(5.4)$ & $6 \cdot 0(3 \cdot 5)$ \\
\hline & $6.4(9 \cdot 3)$ & $3.5(5.4)$ & $4 \cdot 3(5 \cdot 7)$ & $4 \cdot 5(3 \cdot 4)$ \\
\hline & $170(14)$ & $172(-)$ & $166(14)$ & $174(15)$ \\
\hline
\end{tabular}

Mean values $\pm 1 \mathrm{SD}$.

*From Anderson (1972). prevalence of hypersensitivity to A. fumigatus than did those children with normal airways lability (Table 5), as well as a lower MMFR $(t=3.69$; $\mathrm{P}<0.02)$. The prevalence of hypersensitivity to allergens other than $A$. fumigatus was similar in the 2 groups.

The parents of CF children taking similar exercise to the control adults, had a lower mean heart rate at the end of exercise than did the control subjects $(t=2 \cdot 2 ; \mathrm{P}<0.05)$. This difference $(8$ beats $/ \mathrm{min})$ may be explained by the difference in mean ages of the $\mathbf{2}$ groups, as the mean maximum heart rate at 36 years ( 187 beats/min) is 9 beats/min less than at 22 (Astrand and Rodahl, 1970).

\section{Discussion}

Atopy and CF. The association between $\mathrm{CF}$ and allergic disorders of the respiratory tract has been a topic of discussion for many years. Largely retrospective studies suggested an incidence of respiratory tract allergy of $10-14 \%$, little different from normal (Abbott et al., 1951; Van Metre et al., 1960). Later studies which used skin testing to define allergy gave a higher prevalence of $17-24 \%$ (Kulczycki et al., 1961; Rachelefsky et al., 1974). Recently, studies which included tests for hypersensitivity to $A$. fumigatus, have given prevalence rates for atopy of 56-77\% (Allan et al., 1975; Counahan and Mearns, 1975; Warren et al., 1975; Warner et al., 1976a).

In the present study the relatively high prevalence of atopy in children with CF was not due to hypersensitivity to the common allergens $D$. pteronyssinus and grass pollen (the 'normal' pattern of atopic hypersensitivity), as the children were no more frequently sensitive to these allergens than were normal schoolchildren (Godfrey and Griffiths, 1976). In fact, the data of Warren et al. (1975) and Warner et al. (1976a) contain very similar figures for mite and pollen hypersensitivity in $\mathrm{CF}$, but this information is disguised by the high prevalence of Aspergillus

Table 5 Clinical features in relation to exercise-induced airways lability in CF children

\begin{tabular}{lcc}
\hline & \multicolumn{2}{c}{ Airways lability } \\
\cline { 2 - 3 } & Normal & High $\dagger$ \\
\hline No. & 28 & 8 \\
Age (years)* & $8 \cdot 5(4 \cdot 3)$ & $8 \cdot 8(3 \cdot 6)$ \\
Chest $x$-ray score* & $7 \cdot 3(4 \cdot 2)$ & $8 \cdot 1(6 \cdot 3)$ \\
PEFR (\% predicted)* & $92(23)$ & $76(29)$ \\
MMFR (\% predicted)* & $62(27)$ & $30(15)$ \\
Sensitive to & $10(36 \%)$ & $5(63 \%)$ \\
$\quad$ A. fumigatus & $10(36 \%)$ & $2(25 \%)$ \\
Other allergens & &
\end{tabular}

* Mean value \pm SD.

†Fall in PEFR of over $10 \%$ after exercise. 
hypersensitivity. Thus homozygosity for the CF gene was not associated with atopic hypersensitivity of the 'normal' pattern either in the present study, or in the studies of Warner et al. (1976a). Similarly, in the present study, the parents of children with CF were no more frequently atopic than a group of normal young adults (Table 2). We thus found no evidence to support the hypothesis put forward by Warner et al. (1976b) that hererozygosity for the CF gene was associated with atopy. There are two reasons to suspect that the study of Warner $e t$ al. (1976b) gave misleading results. Firstly, Warner et al. relied for adult controls on self-selected friends of CF parents, only 25 of whom were actually skintested, leaving much room for bias. Secondly, their study was carried out at a specialist referral centre with a highly selected group of CF patients, unrepresentative of $\mathrm{CF}$ patients and their families in general.

Hypersensitivity to $A$. fumigatus was numerically important in the present study and was clearly associated with severe lung disease (Table 3). Its prevalence appeared to increase with age, up to 13 years (Figure), in contrast to the normal prevalence of 'normal pattern' atopy which was affected little by age. These observations suggest that hypersensitivity to A. fumigatus may be secondary to lung disease, although it would appear that atopic children with CF are more likely to acquire hypersensitivity to $A$. fumigatus than are nonatopic children. (This is not surprising, as Warren et al. (1975) showed that immediate hypersensitivity to A. fumigatus in CF is mediated by IgE.) The suggestion of Warner et al. (1976a) that allergy in CF is associated with severe chest disease is probably an over simplification, since they do not distinguish between allergy to commonly sensitising antigens and allergy to $A$. fumigatus.

Although numbers were small, it would appear that the CF children with the best overall clinical condition were those who were atopic but who had not yet developed hypersensitivity to $A$. fumigatus (Table 3). This association between 'allergy' (Van Metre et al., 1960), or atopy (Rachelefsky et al., 1974), and relatively mild CF has previously been noted. However, it cannot be concluded that atopic CF children have a better long-term prognosis than do nonatopic CF children, because it would appear that the atopic group are more likely eventually to develop $A$. fumigatus hypersensitivity and, by association, severe lung disease. A longitudinal study of CF in children would be necessary to demonstrate this.

Airways lability in cystic fibrosis. Airways obstruction in $\mathrm{CF}$ is largely fixed in character. A small and variable response has been shown to sympathomimetic drugs (Featherby et al., 1970; Zapletal et al., 1971; Landau and Phelan, 1973), particularly when the effort-independent indices have been measured. In response to exercise, many children with CF have been reported to develop airways obstruction (Day and Mearns, 1973; Counahan and Mearns, 1975). A fall in PEFR of greater than $10 \%$ after a standard treadmill running test has been considered to indicate abnormal degree of lability (Silverman and Anderson, 1972), and by this criterion $8(22 \%)$ out of 36 CF children in the present study were abnormal. This is somewhat less than the $40 \%$ reported by Counahan and Mearns (1975) using an identical test. Using a free-range running test, known to provoke greater fall in PEFR than treadmill running (Anderson et al., 1971), Day and Mearns (1973) demonstrated significant airways lability after exercise in $46 \%$ of their patients. The bias introduced by these workers studying patients at a referral centre could account for the difference from the present study. The figure of $22 \%$ of abnormally labile CF children may reflect the true situation in relatively unselected patients.

In asthmatic children the severity of exercise determines the degree of subsequent airways lability (Silverman and Anderson, 1972). In the present study the target heart rate of $170 / \mathrm{min}$ may have been produced by less energy expenditure in the more severely affected patients. This may have produced a lower prevalence of airways lability than would have been found had fixed work loads been used.

The present study confirms the observations of Day and Mearns (1973) that those children with apparently greater airways lability had more severe lung disease. Since the fall in PEFR after exercise is expressed as a proportion of the initial value, it could be argued that in those CF children who initially had severe airways obstruction (hence a low PEFR), a relatively small fall in PEFR after exercise would produce a spuriously high value for exercise-induced airways obstruction. However, in asthmatic children, exercise-induced asthma has been shown to be independent of the severity of airways obstruction in individual subjects (Silverman, 1973). If this applies also to children with CF then the association between airways lability and severe lung disease was a real phenomenon. If it does not apply, the prevalence of exercise-induced airways lability in CF would have been even lower than the $22 \%$ found here. It is not known which alternative is correct and it is therefore unhelpful to try to identify exercise-induced airways lability in individual CF children who have significant airways obstruction at rest.

As noted by Jones (1975) in his comment on the paper of Counahan and Mearns (1975), the rise in 
PEFR during exercise is greater when the initial PEFR is low. There is therefore no useful information to be gained by studying the rise in PEFR during exercise. However, an estimate of airways lability in CF patients who have little airways obstruction at rest may help in understanding their disability, and may occasionally permit the rational trial of bronchodilator drugs.

\section{Conclusions}

There was no association between the 'normal' pattern of atopy and the possession of a CF gene either by children with $\mathrm{CF}$ or their parents. Hypersensitivity to $A$. fumigatus was common in CF children and was associated with severe lung disease. The precise relationship between severe lung disease and hypersensitivity to $A$. fumigatus remains to be elucidated by detailed prospective studies. However, the importance of $A$. fumigatus sensitivity seems likely to increase as patients with CF survive longer, and these patients may be at risk of developing allergic bronchopulmonary aspergillosis. Early recognition of this difficult condition may be aided by prior knowledge of the atopic status of CF children, since Aspergillus hypersensitivity is more likely to develop in a previously atopic child.

In a condition such as CF in which a history of wheezing may be of little help in the recognition of coexisting asthma, the exercise test, a simple and reliable method of demonstrating airways lability, may be of help in management, although there are difficulties in the interpretation of exercise-test results in patients with severe airways obstruction.

We thank the paediatricians of the Avon area for their co-operation.

\section{References}

Abbott, V., McCrearey, J. F., Pocock, R., and Brown, A. (1951). Fibrocystic disease of the pancreas. Canadian Medical Association Journal, 64, 419-423.

Allan, J. D., Moss, A. D., Wallwork, J. C., and McFarlane, H. (1975). Immediate hypersensitivity in patients with cystic fibrosis. Clinical Allergy, 5, 255-261.

Anderson, S. D. (1972). Physiological aspects of exerciseinduced bronchoconstriction. PhD thesis, University of London.

Anderson, S. D., Connolly, N., and Godfrey, S. (1971). Comparison of bronchoconstriction induced by cycling and running. Thorax, 26, 396-401.

Astrand, P. O., and Rodahl, K. (1970). Textbook of Work Physiology. McGraw-Hill: New York.

Chrispin, A. R., and Norman, A. P. (1974). The systematic evaluation of the chest radiograph in cystic fibrosis. Pediatric Radiology, 2, 101-106.

Cogswell, J. J., Hull, D., Milner, A. D., Norman, A. P., and Taylor, B. (1975). Lung function in childhood. III.
Measurement of airflow resistance in healthy children. British Journal of Diseases of the Chest, 69, 177-187.

Cotes, J. E. (1975). Lung Function. Blackwell: London.

Counahan, R., and Mearns, M. B. (1975). Prevalence of atopy and exercise-induced bronchial lability in relatives of patients with cystic fibrosis. Archives of Disease in Childhood, 50, 477-481.

Day, G., and Mearns, M. (1973). Bronchial lability in cystic fibrosis. Archives of Disease in Childhood, 48, 355-359.

Featherby, E. A., Weng, T. R., and Levison, H. (1970). The effect of isoproterenol in airway obstruction in cystic fibrosis. Canadian Medical Association Journal, 102, 835-838.

Godfrey, R. C., and Griffiths, M. (1976). The prevalence of immediate positive skin tests to Dermatophagoides pteronyssinus and grass pollen in school children. Clinical Allergy, 6, 79-82.

Godfrey, S., Kamburoff, P. L., and Nairn, J. R. (1970). Spirometry, lung volumes, and airway resistance in normal children aged 5 to 18 years. British Journal of Diseases of the Chest, 64, 15-24.

Jones, R. S. (1975). Letter: Bronchial lability in cystic fibrosis. Archives of Disease in Childhood, 50, 909.

Kulczycki, L. L., Mueller, H., and Schwachman, H. (1961). Respiratory allergy in patients with cystic fibrosis. Journal of the American Medical Association, 175, 358-364.

Landau, L. I., and Phelan, P. D. (1973). The variable effect of a bronchodilating agent on pulmonary function in cystic fibrosis. Journal of Pediatrics, 82, 863-868.

McFarlane, H., and Allan, J. D. (1976). Letter: Cystic fibrosis heterozygosity in pathogenesis of allergy. Lancet, 1,1241 .

Pepys, J. (1975). Skin testing. British Journal of Hospital Medicine, 14, 412-417.

Rachelefsky, M. S., Osher, A., Dooley, R. E., Ank, R., and Stiehm, R. (1974). Coexistant respiratory allergy and cystic fibrosis. American Journal of Diseases of Children, 128, 355-359.

Silverman, M. (1973). Exercise studies in asthmatic children. MD thesis, University of Cambridge.

Silverman, M., and Anderson, S. D. (1972). Standardisation of exercise tests in asthmatic children. Archives of Disease in Childhood, 47, 882-889.

Swinscow, T. D. V. (1977). Statistics at Square One. British Medical Association: London.

Van Metre, T. E., Jr, Cooke, R. E., Gibson, L. E., and Winkenwerder, W. L. (1960). Evidence of allergy in patients with cystic fibrosis of the pancreas. Journal of Allergy, 31, 141-150.

Warner, J. O., Taylor, B. W., Norman, A. P., and Soothill, J. F. (1976a). Association of cystic fibrosis with allergy. Archives of Disease in Childhood, 51, 507-511.

Warner, J. O., Norman, A. P., and Soothill, J. F. (1976b). Cystic fibrosis heterozygosity in the pathogenesis of allergy. Lancet, 1, 990-991.

Warren, C. P. W., Tai, E., Batten, J. C., Hutchcroft, B. J., and Pepys, J. (1975). Cystic fibrosis-immunological reactions to $A$. fumigatus and common allergens. Clinical Allergy, 1, 1-12.

Zapletal, A., Motoyama, E. K., Gibson, L. E., and Bouhuys, A. (1971). Pulmonary mechanics in asthma and cystic fibrosis. Pediatrics, 48, 64-72.

Correspondence to Dr M. Silverman, Department of Paediatrics and Neonatal Medicine, Hammersmith Hospital, DuCane Road, London W12 0HS. 